\title{
Audiology Neuro-Otology
}

Ahrens, S. 386

Bakin, J.S. 143

Berg, P. 181

Brandt, T. 61

Büttner, U. 61

Büttner-Ennever, J. 61

Ceranic, B.J. 332

Charles, B. 373

Chéry-Croze, S. 240

Collet, L. 240

Elbert, T. 181

Eura, Y. 253

Filippich, L. 373

Freeman, S. 40, 349

Gartner, M. 240

Gleich, O. 1

Hackett, T.A. 73

Harel, N. 212, 361

Harrison, R.V. 212, 281, 361

Hartmann, S. 386

Hashino, E. 229

Hatzopoulos, S. 402

Heinecke, A. 386

Hirakawa, H. 361

Hoke, E.S. 300

Hoke, M. 300

Huffelen, W.M. van 419
Irvine, D.R.F. 121

Kaas, J.H. 73

Kadow, C. 1

Kakigi, A. 212, 361

Kato, T. 253

Khvoles, R. 40, 349

Kirk, D.L. 21

Koch, D.B. 166

Kraus, N. 166

Krishnan, A. 291

Lamprecht-Dinnesen, A. 386

Lütkenhöner, B. 189, 265

Luxon, L.M. 332

McDaniel, S.S. 291

McGee, T.J. 166

Marini, F. 54

Martini, A. 402

Mateijsen, N.J.M. 419

Mazzoli, M. 402

Meric, C. 240

Morizono, T. 253

Mount, R.J. 212, 281, 361

Mühlnickel, W. 300

Müller, E. 386

Murdoch, B. 373

Pantev, C. 181

Pohl, M. 386

Prasher, D.K. 332

Prosser, S. 402
Quaranta, A. 54

Rajan, R. 121

Rauschecker, J.P. 86

Raveh, E. 212

Riebandt, M. 386

Rockstroh, B. 181

Rosignoli, M. 402

Ross, B. 181, 300

Sakata, T. 253

Sallustio, V. 54

Salvi, R.J. 229

Schreiner, C.E. 102

Shibata, K. 253

Shiraishi, K. 253

Sockalingam, R. 373

Soda, T. 253

Sohmer, H. 40, 349

Sommerlad, S. 373

Steinsträter, O. 189, 265

Strutz, J. 1

Takeno, S. 281

Trautwein, P.G. 229

Wake, M. 281

Weinberger, N.M. 143

Wit, H.P. 419

Yates, G.K. 21

\section{KARGER}

(c) 1998 S. Karger AG, Basel

Fax + 41613061234

E-Mail karger@karger.ch

www.karger.com

Accessible online at:

http://BioMedNet.com/karger 